\title{
Bearing Gods in Mind and Culture
}

The journal Religion, Brain \& Behavior was founded in order to foster multidisciplinary research on religion that reaches across fields as diverse as neuroscience, evolutionary biology, moral psychology, cultural anthropology, cognitive archaeology and political science. In what follows I will continue referring to the conceptual arena in which these (and other) disciplines meet and interact to clarify our understanding of religious belief, behavior, and experience as the "bio-cultural study of religion." This nomenclature is not intended to demarcate a new singular academic field or discipline.

Given the astonishing fecundity of the open integration and overlapping application of evolutionary, cognitive, and social scientific theories and research methods to religious phenomena, trying to set such boundaries would seem counterproductive. If we think of this as a "field," the metaphor should be construed not in geographical but in physical terms: a dynamic force field of interconnected and open explanatory events. If we think of this as a "discipline," the focus should not be on deciding its departmental location but on disciplining ourselves to remain interconnected and open during every event of explanation.

This chapter illustrates the weaving together of the two broad conceptual threads introduced above, which are increasingly being integrated into theoretical patterns within the disciplined fields of the bio-cultural study of religion, in four books published in 2010: David Lewis-Williams' Conceiving God, Pascal Boyer's The Fracture of an Illusion, Scott Atran's Talking to the Enemy, and Matt Rossano's Supernatural Selection. After comparing and contrasting the approaches of these authors, I conclude by briefly calling attention to the contemporary psychological, political, and philosophical relevance of these developments. We will return to these issues in other chapters throughout the book.

A convergence of insights from a variety of sciences is leading a growing number of scholars to argue that religion (whatever else it may include) typically involves shared imaginative engagement with supernatural agents who

1 My use of this phrase is inspired by the name of the Institute that helped found the journal: The Institute for the Bio-Cultural Study of Religion (www.mindandculture.org/focus-areas/ religion). This chapter is an adapted version of "Bearing Gods in Cognition and Culture," originally published in Religion, Brain \& Behavior 1, no. 2 (2011).

(C) F. LERON SHULTS, 2018 | DOI 10.1163/9789004360952_003

This is an open access chapter distributed under the terms of the CC BY-NC-ND 4.o license. Shults - 9789004360952 
are born through naturally evolved human cognitive functioning and borne by culturally transmitted human coalitional functioning. By "supernatural agents" I mean disembodied wielders of causal power, i.e., discarnate intentional entities that are not susceptible to normal scientific empirical observation or measurement. ${ }^{2}$ Although the term "god" commonly refers to beings like Zeus, Yahweh, or Buddhist devas, in this literature one increasingly finds it used to indicate supernatural agents in general, including ghosts, angels, saints, jinn, etc. ${ }^{3}$ I follow this usage in this context for the sake of simplicity.

As we saw in Chapter 1, there is a burgeoning literature within the bio-cultural study of religion that supports the claim that gods are born(e) in minds and cultures as a result of evolved cognitive and coalitional biases. This chapter provides a different sort of introduction to this literature: a review of the four influential books identified above, all published in 2010. One reason for choosing monographs instead of articles is that the former provide authors with more space (and license) to explore the wider implications of their empirical efforts. Before briefly expositing, comparing, and contrasting these four representative theoretical contributions, I first outline in more detail the two threads that we will find woven into their work in various ways.

\section{Anthropomorphic Promiscuity and Sociographic Prudery}

The books we discuss below are examples of the way in which the bio-cultural study of religion is providing answers to the questions "Where do supernatural agents come from?" and "Why do they stay around?" Religions have their own answers to these questions, sometimes even developing complex theogonies, i.e., narratives about the birth of the gods and their connections to particular human families or other coalitions.

Although scientists have long been interested in naturalistic descriptions of this phenomena, in the last two decades empirical research across disciplines has led to integrative and compelling explanations of what I call the theogonic (god-bearing) mechanisms of anthropomorphic promiscuity and sociographic prudery. As we have seen, these include traits that foster the hyper-sensitive detection of agential forms in nature and the hyper-sensitive protection of

2 This use of the phrase "supernatural agent" is derived and adapted from Wildman, Science and Religious Anthropology. (Ashgate, 2009).

3 See, e.g., Barrett, Why Would Anyone Believe in God? (Walnut Creek, CA: AltaMira Press, 2004); Tremlin, Minds and Gods (Oxford University Press, USA, 2010). 
coalitional forms in culture. ${ }^{4}$ Although they differ in their emphases and formulations of these naturally evolved human tendencies, in one way or another each of the authors reviewed below has something to say about both sorts of theogonic mechanism and the complex interactions among them.

Most human beings are naturally promiscuous in their seeking out of human forms in the natural environment. The natural selection of cognitive processes that were overly sensitive to detecting agency contributed to our ancestors' survival. Imagine an early hominid perceiving some ambiguous movement in the forest. Interpretations of such movements as caused by the presence of a potential enemy (or a potential mate) will usually be wrong; however, in those cases where a person is in fact present, failing to guess "relevant agent" can be fatal (or counter-productive in other ways). Individuals with a perceptual strategy that led them to guess "person" may have more often been wrong than individuals who automatically guessed "wind" until more compelling evidence emerged for an intentional cause. The latter, however, would have been less likely to survive in the early ancestral environment than the former. And so it makes sense that this sort of trait, which fostered anthropomorphic promiscuity, would have been naturally selected.

This helps to explain why even today we are ever on the lookout for human (and other) agents, seeing faces in the clouds and mistaking boulders for bears. ${ }^{5}$ Scientists use a variety of terms to refer to this overeager interpretation of ambiguous natural phenomena in terms of agency, intentionality and purposiveness. ${ }^{6}$ All four of the 2010 monographs reviewed below argue that this hyper-sensitivity played a role in the detection of imagined supernatural agents, thereby contributing to the origin and evolution of religion.

Gods may be born in human minds through anthropomorphic promiscuity, but it takes a more or less faithful village to raise (maintain and sustain) them. As we have seen, supernatural agents are borne in human communities (in part) because their imagined presence helps protects in-group cohesion. Over-detecting human minds emerge and are implicated within fields of social relations, which are always and already inscribed with proscriptions and prescriptions. Those groups that survived the last ice age were those whose

4 See also Shults, "Science and Religious Supremacy: Toward a Naturalist Theology of Religions," in Science and the World's Religions, Volume III: Religions and Controversies, ed. Wildman and McNamara (New York: Praeger, 2012).

5 Guthrie, Faces in the Clouds: A New Theory of Religion (Oxford University Press, 1993).

6 Pyysiäinen, Supernatural Agents: Why We Believe in Souls, Gods and Buddhas (Oxford University Press, 2009); Kelemen, "Why Are Rocks Pointy? Children's Preference for Teleological Explanations of the Natural World," Developmental Psychology 35, no. 6 (1999). 
inscription of the socius was reinforced by a prudish over-protection of the coalition's norms by its members, including a willingness to punish defectors and use violence against out-group competitors.

These and other components of sociographic prudery were reinforced over time by the transmission of beliefs in gods who were interested in the coalition, watching its members and capable of bringing health or misfortune. Of course gods do not look the same in every culture. No supernatural agent conceptions are immaculate. Ideas of discarnate intentional entities gestate within a particular social matrix whose historical development influences their ontogenesis; cultural birth marks on the human mind. Whether or not ontogeny recapitulates phylogeny, it seems clear that theogony capitulates to ethnogeny. The fact that all known human cultures, past and present, have been characterized by widespread imaginative engagement with a diversity of supernatural agents is partially explained by the fact that all of their members were Homo sapiens, whose shared phylogenetic inheritance includes evolved mechanisms that naturally reproduce gods who hold us together - psychologically and politically.

Each of the authors discussed below is sensitive to the fact that their empirical findings and theoretical reflections intensify the apparent opposition between science and religion, although they deal with that tension in different ways. Highlighting the two conceptual threads identified above makes it easier to understand this tension. Scientists ( $q u a$ scientists) tend to be anthropomorphically prudent, resisting explanations that appeal to supernatural agency, and sociographically promiscuous, preferring modes of inquiry that do not depend on appeals to religious authorities. In the conclusion of this chapter, I will return to the wider significance of this tension for contemporary human life, but first let us illustrate the unveiling of theogonic mechanisms in four major works published in 2010.

\section{Conceiving God}

I begin with David Lewis-Williams' Conceiving God: The Cognitive Origin and Evolution of Religion (2010). Although he does not play with the metaphor of the "birth of God" as I have, his title aptly points to the conceptual pattern briefly introduced above. Building on several of his earlier works, ${ }^{7}$ this volume provides a comprehensive presentation of his argument that religion emerged

7 Lewis-Williams, The Mind in the Cave: Consciousness and the Origins of Art (London: Thames \& Hudson, 2002); Lewis-Williams and Pearce, Inside the Neolithic Mind: Consciousness, Cosmos and the Realm of the Gods, 1 edition (London: Thames \& Hudson, 2009). 
as a result of early humans' mistakenly taking the entopic phenomenal and hallucinatory experiences of some altered states of consciousness as really indicating a supernatural realm, and granting social privilege to "shamans" who were adept at (or susceptible to) having such experiences during which it was believed that they engaged with (or even became) powerful spiritual beings within that realm.

Lewis-Williams is aware of the general hypersensitivity of human beings to detecting agents everywhere, but his focus is on the way in which the detection of particular kinds of agents within intensified inner-directed altered states contributed to belief in the real existence of such agents and their impact on the natural and social worlds of (waking) human life during outer-directed, problem-oriented conscious thought. Combining neurological and psychological research on reported experiences of intensified hypnagogic and hallucinogenic states with archaeological and ethnographic research on cave art and its role in small-scale shamanic societies, Lewis-Williams argues that early humans had the same spectrum of conscious experiences as do contemporary humans. In modern societies, however, many people are less likely than our ancestors to readily accept the relevance and normative significance of altered states such as dreams, visions and induced hallucinations.

For Lewis-Williams, "the body provides raw material for what, in a variety of social contexts, is accepted as some sort of trafficking with supernatural forces or beings." ${ }^{\prime}$ All humans have neurologically generated experiences, but they have to be shared and regulated in a particular way before they can become the foundation for a religion. As the regulation of the alleged interaction between supernatural agents and the members of a coalition was increasingly taken over by shamans, social differentiation became more marked. In human evolution, "religion and social discrimination went hand in hand" (58). LewisWilliams suggests that as human societies became more complex, so did the modes of regulation and control, which eventually led to clerical and political oppression. In other words, the same altered states and social discrimination are at work in the priestly hierarchies that came to characterize later complex literate societies, including our own. This means "the 'origin' of religion is always with us" (138).

Two of the most commonly reported experiences in the intensified trajectory of consciousness as it moves toward the introverted end of the spectrum and into vivid participatory hallucinations are flying (or floating) above the

8 Lewis-Williams, Conceiving God: The Cognitive Origin and Evolution of Religion (London: Thames \& Hudson, 2010), 149. Page numbers in the following paragraphs refer to this book, unless otherwise noted. 
world and descending (or being drawn) through a tunnel or vortex into the depths of the world. Lewis-Williams suggests that these neurologically generated experiences of magical flight and vortex travel led to the belief in a tiered cosmos, which is the most common view of the structure of the cosmos in pre-modern cultures. In an earlier book with David Pearce, Lewis-Williams illustrates the "near universality" of this cosmological pattern with examples from a wide variety of places and times, across every inhabited continent and from the upper Paleolithic to the present. The pre-Columbian inhabitants of Mesoamerica, for example, believed that the world was organized around a great tree that grew out of a mountain, whose branches connected to an upper world and whose roots went down to the underworld. Some Mayan temples were built in correspondence with the idea of tiered cosmos. ${ }^{9}$ The holy texts of the Abrahamic religions also reflect cosmologies that presuppose an upper world (sky, heaven, paradise) and an under world (sheol, hades, hell), both filled with supernatural agents.

Lewis-Williams' hypothesis is relatively straightforward. First, the reason this belief in a tiered cosmos is so common is that it is neurologically generated; early humans were simply exploring their internal states of consciousness and found supernatural agents (promoting anthropomorphic promiscuity). Second, some members of early human groups came to be perceived as having special experiences of or access to these other tiers, and acquired a social power that led to discriminatory structures within the community (promoting sociographic prudery). Shamanism played a regulative role in the evolution of both sorts of theogonic mechanism. The social capital of the shaman was derived from his or her capacity to intentionally enter altered states in order to travel the cosmos and interact with supernatural agents, which people believed enabled him or her to control the movements of animals and the weather (ensuring food), to heal the sick, etc.

When Lewis-Williams suggests that everything we call "religion" can be traced to natural neurological activity in the brain, specifically to the mistaken acceptance of hallucinations during altered states of consciousness as perceptions of a supernatural realm, he does not mean that religion is reducible to this experiential domain. Within every culture humans interpret such experiences differently, leading to a variety of formal and material expressions of what he calls the "belief" and "practice" domains of religion. However, he does mean that these beliefs and practices are built upon false interpretations of brain states, incorrectly postulating a supernatural realm that somehow has direct consequential and normative bearing on the natural world. In Lewis-Williams'

9 See Lewis-Williams and Pearce, Inside the Neolithic Mind, 66-69. 
view, as long as religion maintains ritual practices based upon such beliefs about neurological experiences, no reconciliation between it and science is possible..$^{10}$

\section{The Fracture of an Illusion}

Pascal Boyer comes to a similar conclusion, although it is based on a different set of empirical findings and disciplinary reflections. Perhaps most well known for his popular book Religion Explained, ${ }^{11}$ Boyer was one of the first scholars to produce a relatively complete theory of religion based on cognitive science. ${ }^{12}$ In his earlier books, he drew heavily upon research in cognitive psychology as well as cultural anthropology to support his claim that the recurrence of patterns in religious belief and behavior across cultures can be explained by an aggregate of complex and independently evolved cognitive mechanisms and social strategies, each of which contributed to early human survival.

In The Fracture of an Illusion: Science and the Dissolution of Religion (2010), Boyer summarizes many of his earlier themes but weaves them together in his most explicit challenge to the very notion of "religion." In Religion Explained, he had described religion as the commodification of parasitic knowledge of "airy nothing" by priestly guilds. In his newer book, he insists there is "no such thing" as religion; it is an imaginary object, a "package" that exists only as a postulation or "marketing ploy" of particular religious institutions and office holders. This charge has obvious political, as well as psychological implications, to which we will return, but first let us point to some of the evidence that leads Boyer to the verdict that what we call "religions" are only collections of fragments of a variety of mental capacities and tendencies that evolved as adaptations with other (non-religious) adaptive purposes.

For Boyer, supernatural (religious) concepts are parasitic on natural concepts, which are formed and regulated by cognitive modules that evolved as human beings adapted to their natural environment, producing an "intuitive ontology" that supports implicitand easily accessible assumptions about natural objects and processes. Human cognition automatically activates expectations

\footnotetext{
$10 \quad$ Lewis-Williams, Conceiving God, 2010, 288.

11 Boyer, Religion Explained: The Evolutionary Origins of Religious Thought, (New York, Basic Books, 2002).

12 Boyer, The Naturalness of Religious Ideas: A Cognitive Theory of Religion, (Berkeley: University of California Press, 1994).
} 
and inferences about the latter when they are categorized into particular domains. For example, when we imaginatively place an object into the category or domain Person, we automatically (usually without conscious awareness) infer that the object was born, eats, has a body, pursues goals, etc. We assume that an Artifact was made, and that a Plant grows, but that neither is intentional. One way in which "supernatural" concepts are special, argues Boyer, is that they minimally violate our intuitive expectations about objects in an ontological domain; e.g., a ghost that goes through walls, a statue that bleeds, a tree that listens to people's conversations. ${ }^{13}$

Concepts of supernatural agents, which Boyer insists are the most significant of what we call "religious" concepts, minimally violate domain-level intuitions about the category Person - especially the natural inference that Persons are limited by their physicality or embodiment. However, other inferences from non-violated intuitive assumptions about objects identified as belonging to that domain continue to flow naturally. Once a ghost or spirit is "detected," cognitive mechanisms are immediately activated, leading to the assumption that it has goals, could be interested in what we are doing, and may even want to eat. It may initially seem odd that people would maintain belief in such counterintuitive ideas and transmit them from generation to generation. In fact, however, it is precisely their (minimal) counter-intuitiveness that makes them easier to remember and transmit.

This promiscuous searching for supernatural agents in the natural environment is reinforced by the role they are intuitively assumed to have in the inscription of the social and moral life of the coalition. Mickey Mouse, for example, does not qualify as a god (despite his being minimally counter-intuitive) because he is not imaginatively engaged as an existentially relevant social agent capable of enforcing or enhancing prudent behavior within a coalition. Boyer observes that supernatural agents are often concerned about (and watching) the moral behavior of members of a group; moreover, they typically have the power to bring some misfortune or blessing. Rituals of various kinds the world over involve trying to connect or manage the relation between the natural and the supernatural members of more or less coherently defined coalitions.

Even though religious specialists usually describe the relation between gods and ethical behavior in terms of legislation or exemplarity, psychological studies suggest that people tend to default quickly to what Boyer calls the "interested party" notion of how superhuman agents are connected to morality.

13 Boyer, The Fracture of An Illusion: Science And The Dissolution Of Religion. Frankfurt Templeton Lectures 2008, ed. Grab-Schmidt et al., (Göttingen: Vandenhoeck \& Ruprecht, 2010), 29. Unless otherwise noted, page numbers in the following paragraphs refer to this book. 
Experiments show that when people are pressed to answer questions about the attributes of gods portrayed in practical scenarios, most automatically defer to descriptions of minimally counter-intuitive discarnate human-like agents who may be watching them and desire to help or hurt them, even if they are able to give "orthodox" definitions of gods (which are often maximally counterintuitive; e.g., God is omniscient and impassible) in other contexts (54). Boyer also briefly treats the application of costly signaling theory to religion, but Atran, and Rossano both deal with this in more detail and so I will return to it below. The salient point for the purposes of this review is the way in which Boyer appeals to a variety of mechanisms that contribute to a mutual reinforcement of sociographic prudery and anthropomorphic promiscuity.

Boyer argues that human beings evolved within a "cognitive niche," which makes them more dependent (in comparison with other species) on obtaining and maintaining social information about other human beings. Given the computational constraints of social interaction, he suggests that thinking about absent agents is both necessary and useful. Humans develop a catalog of possible interaction scenarios constructed when other agents are not around, and this makes actual inference in interaction work better. Boyer points to research indicating how frequently children (perhaps even a majority of children) create imaginary friends. Computing the reactions of the imaginary friend helps to train the mind for actual human engagement, building social capacities for coherent interaction with real, embodied friends $\left(3^{2-34}\right)$.

In their latest books, both Lewis-Williams and Boyer are more explicit than ever about the need for frank and open discussions about the psychological and political significance of these new scientific insights into the mechanisms by which gods have been and continue to be born(e) within increasingly complexifying human societies. Lewis-Williams suggests it is virtually inevitable that the growth of science will continue to change people's minds about supernatural agents no matter how much "God's empire strikes back."14 Boyer, on the other hand, believes that the evolutionary mechanisms that have led to the by-product of "religion" are so pervasive that they will probably always have to be accommodated somehow within future secular civilizations, although the health and survival of the latter will require active resistance to theocratic societies that are "versions of Hell on earth."15 Our next author is also an atheist and is equally dismissive of the truth value of religious claims about supernatural agents, but his theoretical approach to (and the practical implications he draws from) the scientific study of religious others differs in significant ways.

14 Lewis-Williams, Conceiving God, 2010, 257.

15 Boyer, The Fracture of An Illusion, 97. 


\section{Talking to the Enemy}

Like Lewis-Williams and Boyer, Scott Atran can be considered one of the founding figures of the multidisciplinary "bio-cultural" approach to religion that has emerged in the last few decades. His special expertise is in anthropology and cognitive science, but he has also done significant work in evolutionary biology, psychology, and public policy studies. Atran's earlier books include Cognitive Foundations of Natural History, ${ }^{16}$ and In Gods We Trust: The Evolutionary Landscape of Religion. ${ }^{17}$ In his more recent (2010) Talking to the Enemy: Faith, Brotherhood and the (Un)Making of Terrorists, Atran incorporates many aspects of his earlier work, but focuses on detailing his recent anthropological research "in the wild" - in contemporary conflict areas such as Palestine, Afghanistan and southeast Asia, where he has interviewed people who knew, or who hope to become, suicide bombers.

Why do people kill and die for "the Cause," i.e., the belief that the world was intended for "our" committed community? Atran observes that this killing and dying is usually not merely for an abstract Cause but for the cause of a specific group, an "imagined family of genetic strangers," whether brotherhood or fatherland, tribe or team. He argues that it is small-group dynamics, such as raising families or playing soccer together, that trump almost everything else as people move through life. ${ }^{18}$ Atran insists that (most) fundamentalists and jihadists are not naïve or sociopathic - like the rest of us, they are typical human actors who are motivated by the evolved need to feel emotionally good and physically safe in small-scale groups. Religion and "quasi-religious" forms of devotion like patriotism and even love for humanity, however, can play a powerful role in mobilizing and orienting this natural motivation.

Like our first two authors, Atran argues that "all religions" involve beliefs in "bodiless but sentient souls and spirits that act intentionally." Also like them he does not hesitate to criticize such beliefs themselves as rationally inscrutable, immune to falsification, and even absurd.

16 Atran, Cognitive Foundations of Natural History: Towards an Anthropology of Science, Reprint edition (Cambridge: Cambridge University Press, 1993).

17 Atran, In Gods We Trust: The Evolutionary Landscape of Religion (Oxford: Oxford University Press, 2002).

18 Atran, Talking to the Enemy: Faith, Brotherhood, and the (Un)Making of Terrorists (HarperCollins, 2010), 33. Unless otherwise noted, page numbers in the following paragraphs refer to this book. 
Imagine creatures who consistently believed that the dead live on and the weak are advantaged over the strong, or that you can arbitrarily suspend the known physical and biological laws of the universe with a prayer. If people literally applied such prescriptions to factual navigation of everyday life they likely would be either dead or in the hereafter in short order - too short for most individuals to reproduce and the species to survive (432).

It seems that ideas of supernatural agents would be counterproductive to survival. So how are the gods conceived and why do they stay around? Atran's answer weaves together the two theogonic mechanisms that I have called anthropomorphic promiscuity and sociographic prudery.

More than Lewis-Williams and Boyer, however, his portrayal of the pattern involves detailed attention to the affective and collective security that religion can provide for people. In his view, this is the key to understanding why religion survives and even thrives more easily than science and secular reasoning in many modern contexts. Atran argues that religion is not naturally selected as an adaptation to the environment; it is not innate to human beings. Rather, it is the result of a "tricking and tweaking" of naturally evolved mental mechanisms and universal sensibilities in our species - a process that "creates religion from cognition." He briefly traces the historical spiral toward ever larger and more complex human polities that was nurtured and sustained by this cultural tricking and tweaking of "various aspects of our biologically evolved cognition in order to cope with a self-generating epidemic of warfare between expanding populations" (39).

Atran points to studies that show how both children and adults spontaneously interpret even the contingent movement of dots and triangles on a computer screen as interacting agents, detecting intentionality and inventing narratives to make sense of their movement. Humans have evolved an automatic and "hair-triggered" detection of agency in ambiguous contexts as a response "to potential threats (and opportunities) by intelligent predators (and protectors)." This also helps to explain why the majority of supernatural agents worldwide tend to be either malevolent deities (on the model of predator) or benevolent deities (on the model of protector). This easily trip-wired tendency to detect agents that might hurt or help us has been manipulated to serve cultural ends that are far from the adaptive tasks for which they evolved, including the collective engagement of existential needs for affective security and anxieties about deception and death (438-440).

These powerful motivations make it an easy move from imagining invisible agents to believing in their actual existence. Once conceived, the gods are 
easily borne within human groups. Atran explains that although, or actually because, these concepts "have no consistent logical or empirical connection to everyday reality" (430), they can provide a mechanism by which ordinary cognitive processes can be exploited to produce passionate displays of commitment to the group. Costly displays of commitment to "preposterous beliefs" are more powerful signals of one's solidarity than commitment to a mundane belief that is verifiable (or falsifiable). Such displays and signals often take the form of participating in (otherwise non-productive) rituals, painful initiation ceremonies and sometimes even lead to a willingness to sacrifice one's life for the group. He suggests "collective commitment to the absurd is the greatest demonstration of group love that humans have devised" (450).

For Atran, religion can be roughly described as a community's costly and hard-to-fake commitment to a counterintuitive world of supernatural causes and beings. Why must the commitment be hard-to-fake? The human capacity to imagine and communicate to others about counterfactual worlds brings with it a greater potential for deception and defection. The latter weaken the ability of a community to survive, especially as it gets larger and more complex. "Clerics, rulers and elders can only intermittently monitor peasants, workers and youth to verify that commitments to God, country and authority are kept" (144). A shared belief in supernatural predators and protectors who can be imaginatively engaged in ways that activate deep human affections, and who are always monitoring the behavior of the coalition's members, provides a powerful solution to this emergent cultural problem. Those who actually believe in such agents (generally) give the most genuine signals of commitment, which strengthens the belief of others and reinforces the cohesion of the community.

Unfortunately, the dark side of in-group cohesion is out-group violence. Ironically, and tragically, the most common reactions to terrorists have simply reinforced (and illustrated) the spiraling effect of these mechanisms that helped our ancestors survive but now threaten our long-term affective and collective security.

\section{Supernatural Selection}

Matt Rossano's Supernatural Selection: How Religion Evolved (2010) is his first book-length offering to the bio-cultural study of religion, but its scope and integrative coherence merit its inclusion in this review. The title might lead one to expect a treatise on intelligent design but as the sub-title suggests, Rossano acknowledges that the evolution of religion can be explained without appeal 
to the actual existence of supernatural agents. Unlike the other three authors, however, he prefers to leave open the issue of the reality of the gods, suggesting that religion is a matter of subjective relationship and so outside the objective realm of science.

I will return to this issue below, but first let us set out his version of the integrated theogonic mechanisms by which the gods are born(e). Rossano provides a concise summary of his hypothesis about the role of supernatural agents in the evolution of religion:

Sometime between the disappearance of Homo sapiens from the Levant (about 100,000 ybp [years before present]) and the Upper Paleolithic in Europe (about 35,000 ybp) some of our ancestors thought up the idea of a supernatural world. The world they envisioned was inhabited by spirits, ancestors, and gods who kept a close eye on them, ready to pounce on the first signs of deviance. The idea was an evolutionary winner. Groups who had it fanned out across the globe and quickly overwhelmed those who didn't. 19

Why did these groups "win"? Once again we find that components of anthropomorphic promiscuity and sociographic prudery are at work. Our ancestors survived (and passed on their genes and cognitive traits to us) because their social and moral life was "supernaturalized," which enhanced the cohesion and health of the coalitions in which they lived in a variety of ways, many of which we have already observed above.

Part of what makes Rossano's contribution so helpful is the clarity with which he tells the story as he weaves together insights from cognitive science, moral psychology, archaeology and other fields. In what follows, I offer a brief summary of his reconstruction of the evolution of religion. Like the other three authors, Rossano argues that humans were moral and social long before they were "religious." Belief in and ritual interaction with supernatural agents was added to human social life relatively recently. By around 500,00o ybp, our hominin ancestors were already socially bonding by singing and dancing around campfires. By around 100,00o ybp, anatomically modern humans (Homo sapiens sapiens) moved out of Africa and into the Levant, i.e., the western part of what we now call the Middle East.

This first time that our ancestors went "out of Africa" they were confronted by groups of Neandertals with whom they had to compete for resources; this

19 Rossano, Supernatural Selection, 6o. Unless otherwise noted, page numbers in the following paragraphs refer to this book. 
and other factors such as adverse environmental conditions led them to return to Africa by around 90,000 ybp. Rossano calls the 30,000 years that followed the "African Interregnum." During this period, our genetic ancestors faced more ecological crises and resource shortages and nearly went extinct. Those small bands of humans that learned new strategies for dealing with intergroup cooperation and competition survived. Slowly, human coalitional forms transitioned from hunter-gatherers in smaller and more egalitarian groups to larger and more socially stratified groups. These larger coalitions required more complex social bonding rituals, which played a crucial role in holding them together.

More than the other authors, Rossano highlights childhood imaginative capacity as a main spring for the conception of supernatural agents. As social life became more complex, human imaginative capacity was enhanced through natural selection. New rituals would have taxed attention and working memory, and as social interaction became more demanding, the fitness advantage would have been with imaginative children. Rossano suggests that as these children grew into more socially intelligent adults, they further enhanced the affective and collective intensity of rituals by incorporating engagement with imagined supernatural agents. With the addition of "the supernatural" to social life, rituals were expanded from simple singing and dancing to more complex rites that involved initiations, trust-building and eventually shamanistic healing.

Being more imaginative may also have been correlated to greater susceptibility to the health-enhancing placebo effects of such rituals. In this sense, religion would have contributed to the physical health of the group. Adding supernatural agents not only made people healthier, argues Rossano, it also made them "nicer." The imagined presence of gods (punitive ghosts, spirits, etc.) helped to motivate people to give up some of their self-interest, and comply with the social norms of the group. It also motivated them to punish those who did not comply, or even those whose costly signals of commitment were not sufficiently convincing. ${ }^{20}$ The presence of supernatural agents who were always watching, and who were social players who had the power to bring misfortune, went a long way toward solving this difficulty of dealing with potential defectors and deceivers. In Where God and Science Meet, ed. McNamara and Wildman (New York: Praeger, 2006). $1(2006)$. 
Such adaptive advantages gave "religious" hominin groups a decisive edge over "secular" groups, who "eventually went extinct" (198). Around 60,00o ybp these thriving groups of anatomically modern and robustly religious humans once again left Africa and entered the Levant. This time they outcompeted all other hominin groups. Between 50-30,000 ybp, the supernaturalization of their social life was further complexified by the emergence of ancestor worship, which was reinforced by religious narratives in which the living and the dead were construed as part of a larger coalition. Such narratives provided justification for the increasingly stratified societies that emerged during the Neolithic and beyond. Rossano's account stops here, but of course the story of the evolution of religion continues, through the emergence of complex literate states and the rise of the major religious traditions of the axial age in east, south and west Asia. Indeed, the story continues, and all of us - scientists engaged in the bio-cultural study of religion included - are inexorably emplotted within it.

\section{The Philosophical, Psychological, and Political Significance of the Bio-Cultural Study of Religion}

All four of the authors just reviewed are active scientists who have gathered empirical data and formulated complex hypotheses about the evolution of religion, cognition, and culture. All four have also explicitly addressed the relevance of their research for some of the major challenges facing contemporary Homo sapiens. In fact, this is increasingly common in the literature in which scientific disciplines overlap in their study of religion. ${ }^{21}$ In my view this is a laudable development. In this concluding section, I briefly point out some of the similarities and differences in the way in which these scientists attempt to bring their work to bear on broader public and academic discourse on significant issues in philosophy, psychology, and politics.

First, it is quite clear that the bio-cultural study of religion has an important role to play in wider debates in the philosophy of science, especially insofar as it confirms the inherently embodied and contextual nature of all human knowledge. It is commonly agreed that science is and ought to be guided by methodological commitments that embrace anthropomorphic prudery and sociographic promiscuity. In other words, scientific experiments and theories

21 See, e.g., Bulbulia et al., eds. The Evolution of Religion: Studies, Theories, \& Critiques (Santa Margarita, Calif: Collins Foundation Press, 2008); Schaller et al., eds., Evolution, Culture, and the Human Mind (New York: Psychology Press, 2009). 
should avoid appealing to supernatural agents or authorities in their causal explanations.

Whether scientists should have a metaphysical commitment to naturalism is more controversial. Our first three authors are relatively straightforward about their metaphysical commitments, which they find reinforced by their empirical and conceptual work. It is implausible to believe that human cognition is somehow conditioned by intercourse with disembodied and intentional wielders of causal power, as the vast majority of human beings have believed, including most philosophers of science from Plato to Descartes.

Rossano stands out from the others in this regard. Although he agrees with the other three that the evolution of religion can be explained naturalistically by the integration of what I have called theogonic mechanisms, and without recourse to appeals to supernatural agency, he is hesitant to deny the existence of the latter. Because science deals only with the "objective realm" and gods are in the "subjective realm" of relational experience, science cannot decide the question of their existence. He insists “you cannot tell someone they don't have a relationship that they are convinced they have ...(or) force someone into a relationship they are not interested in." 22 From the point of view of the philosophy of science, such comments appear to be remnants of early modern and positivist dichotomies such as subject/object and value/fact. Moreover, in my view, arguing about the possibility or even probability of the existence of supernatural agents is a red herring; the discussion should focus on the plausibility of their hypothesized existence. ${ }^{23}$

Second, each of our authors touches on the psychological relevance of the findings of the bio-cultural study of religion. Although he recognizes some of the deleterious effects of belief in gods, Rossano emphasizes, more than the others, the physical and psychological health benefits of religion. As we have seen, Atran also points to the importance of affective security in small-group dynamics, which can indeed be reinforced by shared imaginative engagement with supernatural agents. However, he pays more attention to the negative psychological distress and emotional hostility toward members of out-groups that such engagement can intensify. Boyer rarely points to the potential positive effects of belief in gods. Although he resists simplistic "religion is the sleep of reason" hypotheses, he expresses concern about the "double consciousness"

22 Rossano, Supernatural Selection, 27.

23 This is spelled out in more detail in Shults, "The Problem of Good (and Evil): Arguing about Axiological Conditions in Science and Religion," in Science and the World's Religions, Volume I: Origins and Destinies, ed. Wildman and McNamara (New York: Praeger, 2012), 39-68. See also Chapter 5 below. 
evident in so many contemporary religious people in the secular west. They must express absolute commitment to their beliefs within the context of their religious coalition, but live in the public sphere as though such doctrines are optional or irrelevant.

Lewis-Williams is less tolerant of calls to "respect" those who believe in supernatural agents, referring to members of religious coalitions as "the gullible" rather than "the faithful." He repeatedly points to ways in which taking beliefs in gods seriously can be maladaptive in contemporary life, and to examples of the sanctioning and convoluted justification of "morally repugnant nonsense" that religious elites try to force upon their followers. Unfortunately, this kind of rhetoric can all too easily make things worse, amplifying psychological mechanisms and religious biases that lead people to defend the coalitions with which they identify.

I find Atran's rhetorical approach more promising. More so than LewisWilliams and Boyer, he attempts to empathize deeply with religious people's affective needs. Unlike Rossano, however, Atran then clearly explains why he believes that gods are merely a result of the "tragedy of cognition," a mental by-product of a strategy for dealing with existential anxiety about deception and death. This suggests the need for developing new strategies for managing anxiety within and across religious "families of origin." ${ }^{4}$ Other recent examples of treatments of the psychological significance of the bio-cultural study of religion that do not denigrate the human passion for experiences of intensity include Wildman's Religious and Spiritual Experiences ${ }^{25}$ and Strozier's The Fundamentalist Mindset. ${ }^{26}$

Finally, the political relevance of the bio-cultural study of religion is also explicitly thematized by each of our four authors. For reasons partially connected to his approach to the subject matter, Atran is the most explicit. Throughout his book, he urges public policy makers to take seriously the need for studying "the sacred," which he believes must include ethnographic research and interviews on the ground by qualified scientists. In other words, we must "talk to the enemy" to understand and facilitate healthier ways of inscribing our social lives in a globalizing world. Rossano deals with these concerns briefly at the end of his book, wondering whether it is possible to have the benefits of religion without the intergroup competition out of which it emerged. Boyer

24 Shults, "Transforming Religious Plurality," Studies in Interreligious Dialogue 20, no. 2 (2010).

25 Wildman, Religious and Spiritual Experiences (Cambridge University Press, 2014).

26 Strozier et al., eds., The Fundamentalist Mindset: Psychological Perspectives on Religion, Violence, and History (New York: Oxford University Press, 2010). 
and Lewis-Williams are more expansive in their treatment than Rossano and more expressive in their negative evaluation of the political effects of religion than Atran.

Another recent contribution to the bio-cultural study of religion that bears on this theme is John Teehan's In the Name of God: The Evolutionary Origins of Religious Ethics and Violence. ${ }^{27}$ Although it too was published in 2010 I did not review it above alongside the other four books because it takes a quite different approach that focuses on the study of holy texts, specifically those of the Abrahamic religions. Teehan demonstrates how the ethical codes of these monotheistic traditions are expressions and extensions of, rather than exceptions to, the natural moral intuitions that emerged through the evolution of human brains in social groups. For example, moral commands that seem to elude evolutionary explanations because of their apparent irrelevance for survival, or their radical calls for altruism beyond kin groups, can be interpreted in light of costly signaling theory, which we described briefly above. Teehan also makes a compelling case for the claim that although religion produces powerful examples of altruistic behavior, it also amplifies the mental and social strategies that foster in-group/out-group violence.

Throughout most of this chapter, I focused on illustrating the explanatory power of hypotheses about the role of various components of anthropomorphic promiscuity and sociographic prudery as god-bearing mechanisms in the origin and evolution of religion. Here in the conclusion I have identified another trend within the bio-cultural study of religion: the increasing willingness of scientists to bring their research into wider academic and public discussions about normative concerns. This is a tricky business - as perilous as it is promising. It may not be a trend that all readers of Religion, Brain \& Behavior will want to follow or even applaud. However, I hope that its pages will sometimes include forays into these lively and important conversations. In this way, the journal may be able to contribute in its own way to some of the greatest adaptive challenges facing humanity in its current natural (ecological) and social (global) environment.

The following chapters represent some of my own attempts to show how bringing the insights of the bio-cultural study of religion to bear on these concerns can help us learn to think and to act together in psychologically and politically healthy coalitions - without bearing gods.

27 Teehan, In the Name of God: The Evolutionary Origins of Religious Ethics and Violence, (Malden, MA: Wiley-Blackwell, 2010). 